NASA-CR-202498

Geological Society of America

Special Paper 293

1994

\title{
The large impact process inferred from the geology of lunar multiring basins
}

Paul D. Spudis

Lunar and Planetary Institute, 3600 Bay Area Boulevard, Houston, Texas 77058

\begin{abstract}
The study of the geology of multiring impact basins on the Moon over the past ten years has given us a rudimentary understanding of how these large structures have formed and evolved on the Moon and other bodies. Two-ring basins on the Moon begin to form at diameters of about $300 \mathrm{~km}$; the transition diameter at which multiple (more than two) rings appear is uncertain, but it appears to be between 400 and $500 \mathrm{~km}$ in diameter. Inner rings tend to be made up of clusters or aligned segments of massifs and are arranged into a crudely concentric pattern; scarp-like elements may or may not be present. Outer rings are much more scarp-like and massifs are rare to absent.

Basins display textured deposits, interpreted as ejecta, extending roughly an apparent basin radius exterior to the main topographic rim. Ejecta may have various morphologies, ranging from wormy and hummocky deposits to knobby surfaces; the causes of these variations in morphology are not known, but may be related to the energy regime in which the ejecta are deposited. Outside the limits of the textured ejecta are found both fields of satellitic craters (secondaries) and light plains deposits.

Impact melt sheets are observed on the floors of relatively unflooded basins. Samples of impact melts from lunar basins have basaltic major-element chemistry, characterized by $K$, rare-earth elements (REE), $P$, and other trace elements of varying concentration (KREEP); ages are between 3.8 and $3.9 \mathrm{Ga}$. These lithologies cannot be produced through the fusion of known pristine (plutonic) rock types, suggesting the occurrence of unknown lithologies within the Moon. These melts were probably generated at middle to lower crustal levels.

Ejecta compositions, preservation of pre-basin topography, and deposit morphologies all indicate that the excavation cavity of multiring basins is between about 0.4 and 0.6 times the diameter of the apparent crater diameter. Basin depths of excavation can be inferred from the composition of basin ejecta; this evidence strongly suggests that basin excavation was limited to upper crustal levels and that effective excavation was from levels no deeper than about 0.1 times diameter of the excavation cavity.

A variety of mechanisms has been proposed to account for the formation of basin rings but none of them are entirely plausible. Mechanisms can be divided into two broad groups: (1) forcible uplift due to fluidization of the target; (2) concentric, brittle, fracturing and failure of the target, on regional (megaterraces) to global scales (lithospheric fracturing). Most basin rings are spaced at a constant factor on all planets, namely the famous $\sqrt{ } 2$ relation, first observed between adjacent rings of
\end{abstract}

Spudis. P. D, 1994, The large impact process inferred from the geology of lunar multiring basins, in Dressler, B. O., Grieve, R.A.F., and Sharpton, V. L., eds., Large Meteorite Impacts and Planetary Evolution: Boulder, Colorado, Geological Society of America Special Paper 293. 
the lunar Orientale basin. Because geological evidence supports divergent ringforming models, it may be that the ring-locating mechanism is different from the ring-forming mechanism. Thus, large-scale crustal foundering (megaterracing) could occur along concentric zones of weakness created by some type of resonant wave mechanism (fluidization and uplift); such immediate crustal adjustment could then be followed by long-term adjustment of the fractured lithosphere.

\section{INTRODUCTION}

The nature of the impact process has been inferred through the study of the geology of a wide variety of crater types and sizes on the Earth and other planets. Some of the largest craters known are the multiring basins found in ancient terrains of the terrestrial planets and satellites (e.g., Spudis, 1993). Of these features, basins on the Moon possess the most extensive and diverse data coverage, including morphological, geochemical, geophysical, and sample data. Although many questions remain, study of the geology of lunar basins, particularly over the past ten years (e.g., Spudis et al., 1984, 1988, $1989 \mathrm{a}, 1989 \mathrm{~b}$ ), has given us a first-order understanding of how these large structures have formed and evolved. In the following pages, I summarize what we know about the formation of multiring basins on the Moon, based on my recent synthesis of planetary impact basins (Spudis, 1993).

\section{BASIN MORPHOLOGY}

Craters on the Moon show increasing morphological complexity with increasing size. The feature "basin" is not rigorously defined: the term has been generally applied to impact structures on the Moon larger than about $300 \mathrm{~km}$ in diameter, based mainly on the assumption that features of this size must have originally contained at least one inner ring of peaks. In fact, basins and craters overlap and the diameter at which this transition occurs varies as a function of planet throughout the solar system.

The smallest lunar craters are bowl-shaped and such a morphology persists until diameters exceed about $15 \mathrm{~km}$ (Pike, 1980). Above this size, craters display features such as flat floors, terraced rims, and central uplifts or peaks. Central peak craters, with diameters of tens of kilometers, are a ubiquitous landform on the Moon and on the other terrestrial planets. Central-peak craters on the Moon persist to diameters of 150 to $200 \mathrm{~km}$; part of the reason for the uncertainty of this transition is that fresh craters of larger size are rare on the Moon.

The larger central peak craters (e.g., Langrenus; Fig. 1a) display floor hummocks that apparently become more prominent with increasing crater size (Hale and Grieve, 1982). Eventually, small rings of peaks surround the main, central peak; the morphology of these craters suggests they are incipient basins, or protobasins (Pike, 1982,1983). Protobasins possess some morphologic attributes of basins, in the form of peak rings or ring-like elements, but by all other criteria, are similar to craters, in that they have wall terraces and true cen- tral peaks. Pike (1983) recognized that lunar protobasins follow morphometric trends distinct from complex craters and basins, but possess morphological attributes of both.

The smallest basins on the Moon are those that display at least two concentric rings; Schrödinger (Fig. 1b) is the type example. Schrödinger ( $320 \mathrm{~km}$ diameter) strongly resembles a central-peak crater, except its central uplift is in the form of a discontinuous ring of peaks, rather than a single peak or simple cluster. The peak ring of Schrödinger is not perfectly circular (Fig. 1b); this irregularity of a fresh feature illustrates some of the problems in recognizing and determining the diameters of basin rings, many of which are very degraded and barely visible. The floor of Schrödinger displays fractures and volcanic vents, suggesting that basins that are filled with mare basalt originally may have possessed similar features. Two prominent radial gouges traverse the exterior ejecta deposits of Schrödinger; these features are similar to radial texture observed around the larger basins, such as Imbrium. Such radial texture has long been attributed to radial fractures (e.g., Scott, 1972); an alternative model holds that they are caused during secondary cratering largely by scouring of low-angle ejecta thrown out of the crater late in the excavation process (e.g., Head, 1976). 1 believe that both fracturing and scouring operate, but that the relative importance of each has yet to be determined (Spudis, 1993).

The transition diameter from two-ring to multiring basins is obscure. This uncertainty partly reflects the small sample of

Figure 1 (on following three pages). Typical impact features on the Moon illustrating the crater-to-basin transition. (A) Langrenus (132 $\mathrm{km}$ diameter). Note floor hummocks (arrows) that are precursors to inner rings (e.g., Hale and Grieve, 1982). NASA photo AS8-16-2615. (B) Schrödinger ( $310 \mathrm{~km}$ diameter). Inner ring is hummocky to massive; radial valleys on the ejecta have counterparts in larger basins and appear to be caused by ballistic emplacement of ejecta. NASA photo LO IV-8M. (C) Korolev (450 km diameter). Note small massifs and hummocks (arrows) that delineate an incipient intermediate ring. Main rim shows major collapse feature, possibly a "megaterrace." NASA photo LO I-38M. (D) Orientale (930 km diameter). Basin shows at least 4 rings, including the rim (numbers). Inner basin (inside ring 1), partly covered by basalt, shows impact melt sheet. Outside of rim (ring 4), basin shows wormy to radially textured deposits (ejecta). Note large, outer ring (arrows). NASA photo LO IV-194M. 

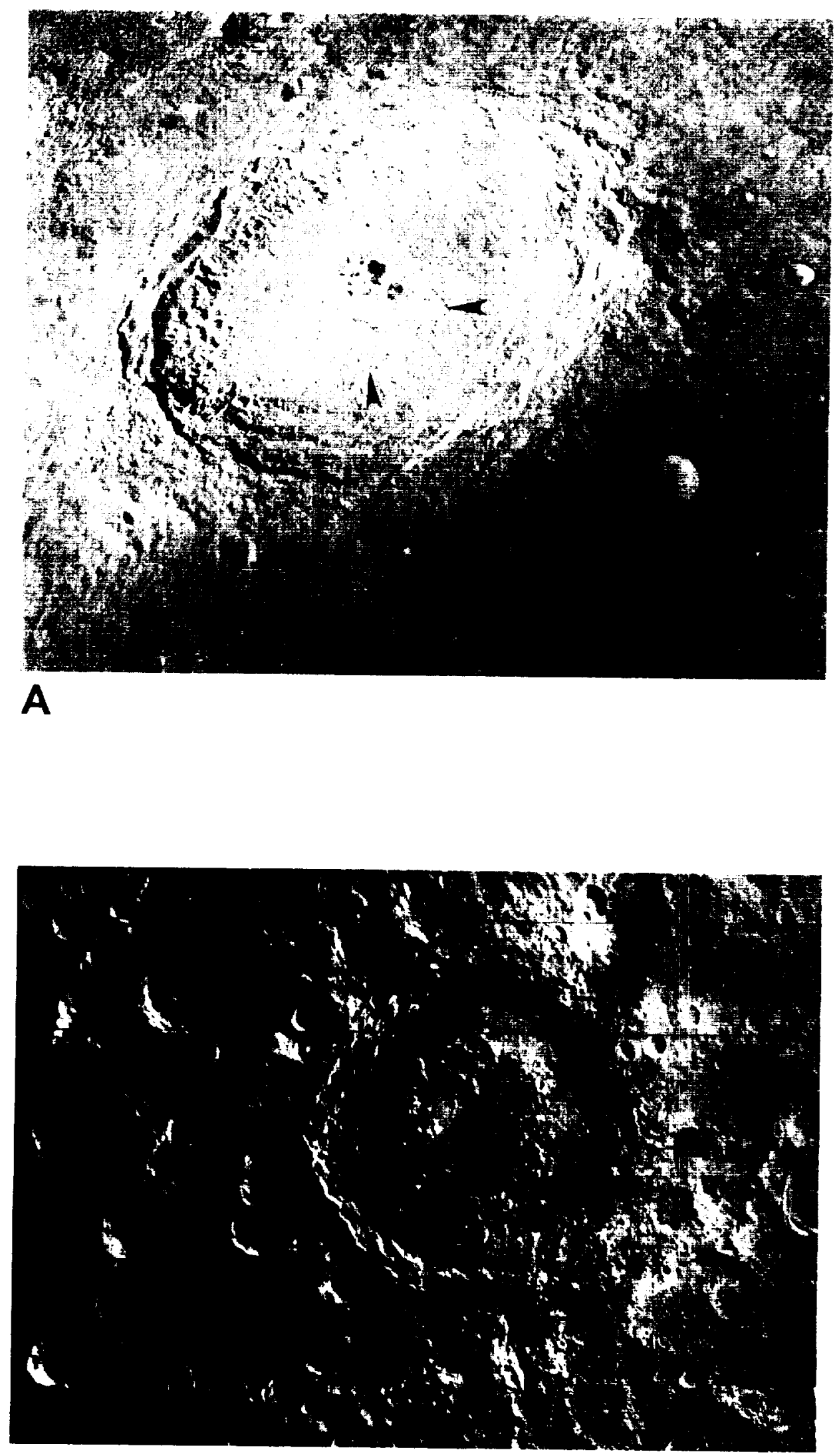

B 


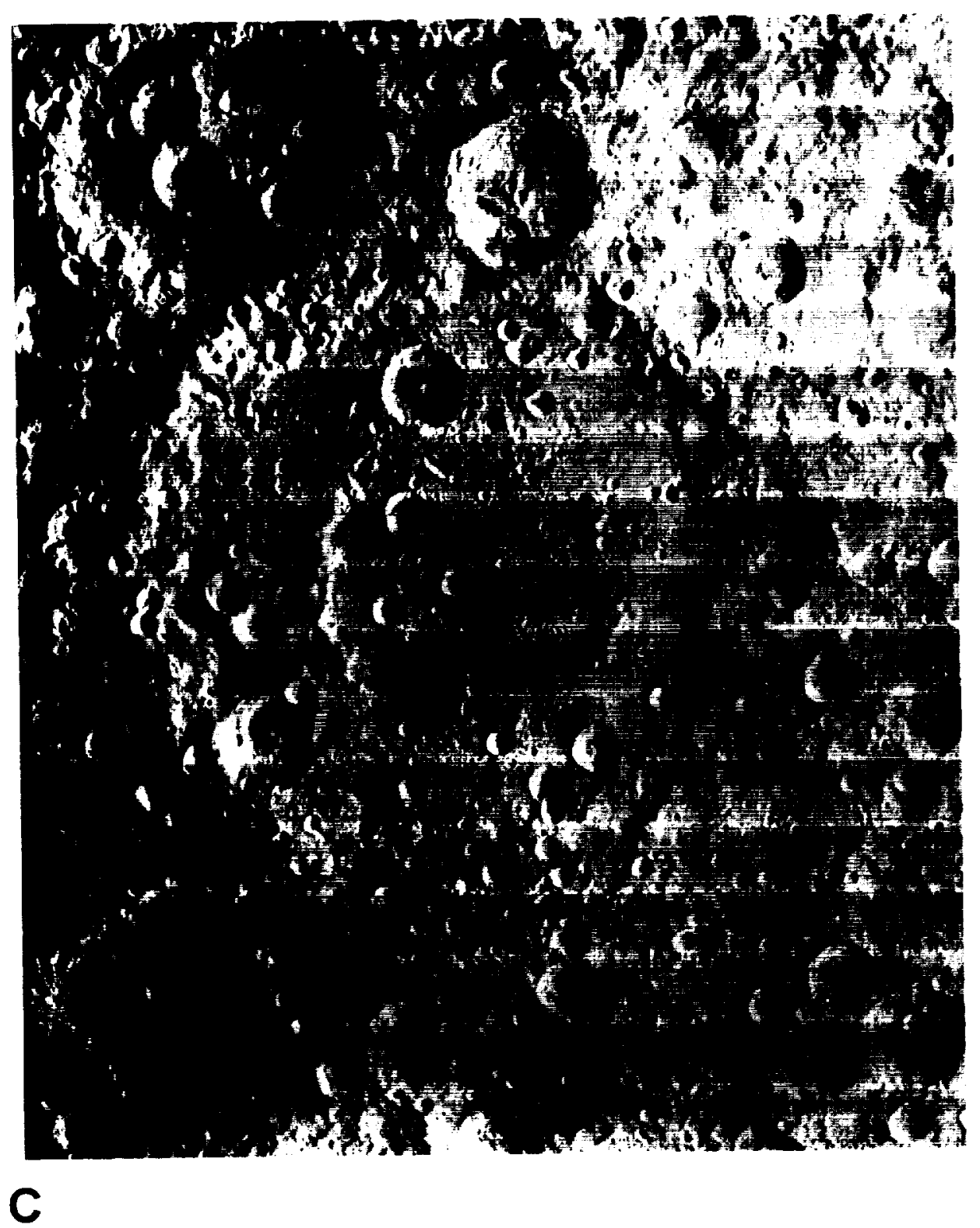

basins in this size range on the Moon (there are only seven basins between $400 \mathrm{~km}$ and $600 \mathrm{~km}$ diameter on the Moon, and the transition lies somewhere within this size range) and their relatively poor state of preservation. However, new mapping of all lunar basins has shown that many of these basins in the $400 \mathrm{~km}$ to $600 \mathrm{~km}$ diameter range, previously thought to be two-ring basins, are in fact, true multiring structures (Pike and Spudis, 1987); a prime example is Korolev (450 km diameter; Fig. 1c). The floor of Korolev shows a series of small peaks between the inner prominent ring and the terraced wall; these peaks tend to be found at constant radial distances from the basin center and probably constitute an incipient intermediate ring of the basin. Additionally, concentric scarps outside the main rim (Fig. 1c) suggest that even larger exterior rings are incipient. Although not well developed, the presence of these features indicates that Korolev is a true, albeit morphologically immature, multiring basin.

The famous Orientale basin (930 km diameter; Fig. 1d) displays all of the classic attributes of multiring basins, including at least four (and possibly as many as six) concentric ring structures. True basins possess multiple rings, some having as few as three and others as many as seven distinct rings (Pike and Spudis, 1987; Wilhelms, 1987; Spudis, 1993). In every basin, one ring appears to be more prominent than the others and is believed to correspond to the topographic rim of complex craters. This ring is known by various names-basin rim of Wilhelms, 1987; Ring IV of Pike and Spudis, 1987; MOR of Croft, $1981 \mathrm{~b}$; it corresponds to the Cordillera ring of the Orientale basin (Fig. 1d).

Rings inside and outside of the basin main ring are recog- 


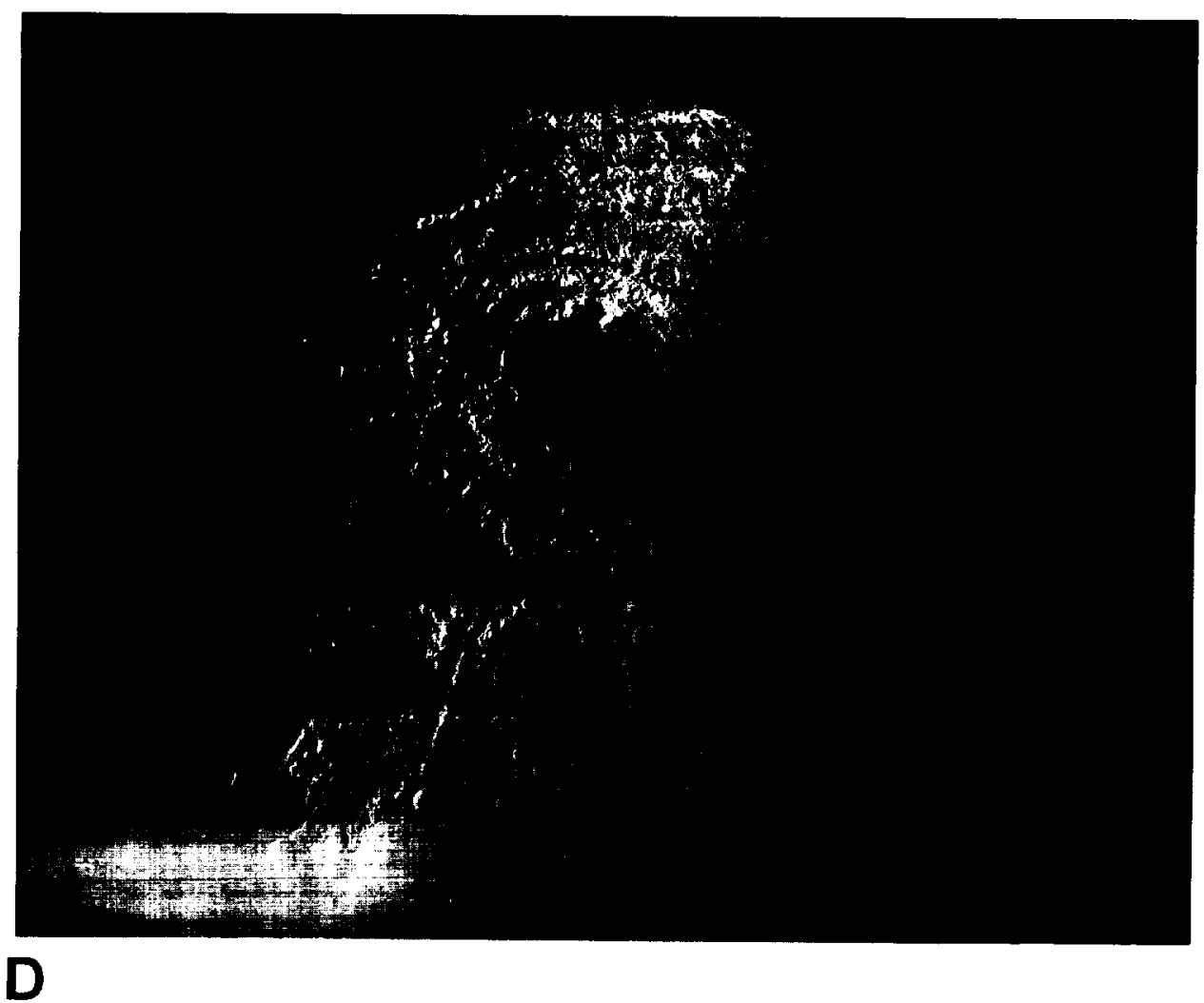

nized, each having distinct morphology. Basin inner rings are clusters or aligned segments of massifs, arranged into a crudely concentric pattern; scarp-like elements may or may not be present (Fig. Id). Basin outer rings are more scarp-like and massifs are rare. Within a certain subset of basins on the Moon, e.g., Crisium (Spudis et al., 1989b) and Humorum (Spudis et al., 1992), the main topographic rim is not evident, either in terms of morphologic or topographic prominence. Such a relation among rings has been cited as resulting from the effects of low-angle, oblique impact (e.g., Wichman and Schultz, 1992). I prefer the interpretation that these basins have undergone a different style of post-impact modification, possibly related to global cooling and the associated rapid increase in the thickness of the lithosphere within the Moon 3.9 Ga ago (Spudis et al., 1989b; Spudis, 1993).

\section{BASIN EJECTA AND IMPACT MELT}

Basins display ejecta deposits, roughly extending an apparent basin radius beyond the main topographic rim. Ejecta surfaces may display various morphologies, ranging from wormy and hummocky (e.g., Hevelius Formation of Orientale; Fra Mauro Formation of Imbrium; Wilhelms, 1987) to knobby (e.g., Alpes Formation of Imbrium; Wilhelms, 1987). At Orientale, knobby material is largely confined within the Cordillera scarp while hummocky materials mostly are found only beyond this boundary (McCauley, 1977; Wilhelms, 1987). However, at Imbrium, both units occur only beyond the topographic rim (Apennine ring) and display a curious "bilateral" double symmetry, whereby knobby Alpes material is confined to the northeast and southwest regions exterior to the rim, and radially lineated Fra Mauro materials are found mostly in the southeast and northwest of the rim exteriors (Spudis et al., 1988; Spudis, 1993); this relation remains unexplained. Fields of satellitic craters (secondaries; Oberbeck, 1975; Wilhelms, 1976) and light plains deposits (Cayley Formation; Wilhelms, 1987) are found outside the limits of the basin textured ejecta.

The morphology of basin deposits is probably controlled in some way by the energy of their environments of deposition. Near the rim of the basin, late-stage excavation is lowenergy and proximal units display hummocky, dune-like morphology (e.g., the Descartes material of Nectaris basin, Spudis, 1984; and Apenninus material of the Imbrium basin, Spudis et al., 1988). Away from the basin rim, the higher energy environment producing the distal continuous deposits forms undulating, lineated, knobby, or smooth deposits, such as the Fra Mauro and Alpes Formations of the Imbrium basin (Spudis et al., 1988). Isolated patches of primary ejecta from the basin that occur within the discontinuous deposits may also have this appearance (e.g., the Sculptured Hills material on the eastern rim of Serenitatis, which may be partly related to the Imbrium basin; Spudis and Ryder, 1981). The depositional environment with the highest energies is associated with the discontinuous facies of basins, which occur at great distances from the basin rim and consist of large secondary 
craters, crater chains and clusters, and smooth plains. In this zone of basin deposits, the volume of locally derived ejecta from secondary craters exceeds the amount of primary ejecta (Oberbeck, 1975) and energetic mixing of the two components produces a complex, polymict deposit.

Impact melt sheets are observed on the floors of relatively unflooded basins, such as Orientale (McCauley, 1977; Wilhelms, 1987) and presumably are buried by later deposits of mare basalt in more deeply filled and degraded basins (Wilhelms, 1987). Melt sheets mantle basin topography and tongues of extruded melt can be seen in many areas, segregating from the main sheet. The sampling of basin material (including impact melt) was a high priority target for the Apollo missions (Wilhelms, 1993). A class of impact melts in the Apollo sample collections possessing basaltic major-element chemistry has a KREEP trace-element pattern of varying concentration, and all of the impact melts have ages of about 3.8-3.9 Ga (Spudis et al., 1991; Spudis, 1993). These rocks, collectively called "low-K Fra Mauro" basalt or basaltic impact melts, are probably generated during basin-forming impacts (Ryder and Wood, 1977; McCormick et al., 1989; Spudis et al., 1991).

A large amount of information, including compositions, ages of formation, and regional distribution and geological setting (summarized in Spurdis, 1993), has been collected for these basaltic impact melts on the Moon. Several melt groups are found at the Apollo landing sites (Fig. 2); although only data for the elements $\mathrm{Ti}$ and $\mathrm{Sc}$ are shown, these groupings also appear well defined in other chemical plots (Ryder and Spudis, 1987). Note that with the exception of the Apollo 17 aphanites (and "group" A of Apollo 15, a three-member collection), the melt compositions appear to form diversity envelopes of size roughly comparable to each other end and to the terrestrial Manicouagan impact melt sheet (Fig. 2). However, the groups also cluster by site, with the Apollo 16 melts making up a diffuse group with low Ti and Sc (groups 1-3, Fig. 2), the Apollo 17 melts having moderate $\mathrm{Ti}$ and high $\mathrm{Sc}$ (poikilitic and aphanitic, Fig. 2), and the Apollo 15 melts having high $\mathrm{Ti}$ and Sc (groups A-E, Fig. 2). Finally, note that if the melt groups are considered collectively by site, the resultant landing site envelopes show diversity no greater than that displayed solely by the Apollo 17 aphanitic impact melts (Fig. 2).

In addition to these compositional data, we have learned more about impact melts on the Moon. First, basaltic impact melts are distinct in chemical composition from typical upper crust, as determined by remote sensing; they are both richer in KREEP and transition metals and are more mafic (less Al and more $\mathrm{Mg}$ ) than the anorthositic composition of the upper crust (Taylor, 1982; Spudis and Davis, 1986). Second, all of these melts formed in a very short interval, between about 3.95 and $3.82 \mathrm{Ga}$ ago (e.g., Ryder, 1990). Finally, each of these three Apollo sites are located within, on, or near the rims of three of the largest, youngest (Wilhelms, 1987) basins on the lunar near side: Apollo 17 occurs within the Serenitatis basin (Wolfe and others, 1982), Apollo 15 is on the main rim of the Imbrium basin (Spudis and Ryder, 1985), and Apollo 16 is on the ejecta backslope of the Nectaris basin (Spudis, 1984). Each of these sites is proximate to recognizable deposits of each basin; indeed, such deposits were high priority sampling targets during these missions (Wilhelms, 1993).

Taking the compositional data (typified by Fig. 2) and the above considerations at face value, I suggest that most of the basaltic impact melts in the Apollo collections represent impact melt from the Nectaris (Apollo 16 groups; Spudis, 1984), Serenitatis (Apollo 17 groups; Ryder and Wood, 1977), and Imbrium (Apollo 15 groups; Ryder and Wood, 1977; Spudis et al., 1991) basins. A curious fact about lunar basaltic impact melts is that they cannot be produced through the fusion of known pristine rock types (McCormick et al., 1989; Spudis et al., 1991), suggesting the occurrence of unsampled crustal lithologies on the Moon. Basin impact melts were probably generated at middle to lower crustal levels of the Moon (Ryder and Wood, 1977; Spudis and Davis, 1986), and so these unsampled rock types may be common at depth within the Moon.

\section{BASIN EXCAVATION}

The preservation of older topography within the main topographic rim of a basin provides some constraints on the size of its excavation cavity. At Orientale, pre-existing craters and basins can be mapped (King and Scott, 1978; Schultz and Spudis, 1978; Spudis et al., 1984) within the Cordillera scarp (50 km diameter), and some structures may extend inside the outer Rook ring (620 km diameter; Schultz and Spudis, 1978). These observations suggest that the excavation cavity for Orientale must have been less than about $600 \mathrm{~km}$ in diameter (Spudis et al., 1984). The minimum size is difficult to constrain; the innermost ring $(400 \mathrm{~km}$ diameter $)$ may provide a lower limit to cavity size (Spudis et al., 1984). These constraints observed at the Orientale basin are paralleled by similar preservation of pre-basin topography within the Imbrium basin ( $1,160 \mathrm{~km}$ main rim diameter), where the prominence of the Apennine Bench indicates that the excavation cavity must be less than about $800 \mathrm{~km}$ in diameter (Spudis et al., 1988). Collectively, these data indicate that the excavation cavity of multiring basins is between about 0.4 and 0.6 times the diameter of the apparent crater diameter (Schultz and Spudis, 1978; Spudis et al., 1984, 1988, 1989a; Spudis, 1993).

Approximate depths of excavation for lunar basins can be inferred from the composition of basin ejecta. At Orientale, ejecta are very feldspathic, having a normative composition of noritic anorthosite, and mafic (basaltic) components cannot be present in quantities greater than a few percent (Spudis et al., 1984). Because evidence from other basins (Spudis, 1984; Spudis and Davis, 1986) and impact melts from the Imbrium and Serenitatis basins (Ryder and Wood, 1977) suggest a more mafic crustal composition at depth, this feldspathic composition of Orientale ejecta suggests that excavation here was lim- 


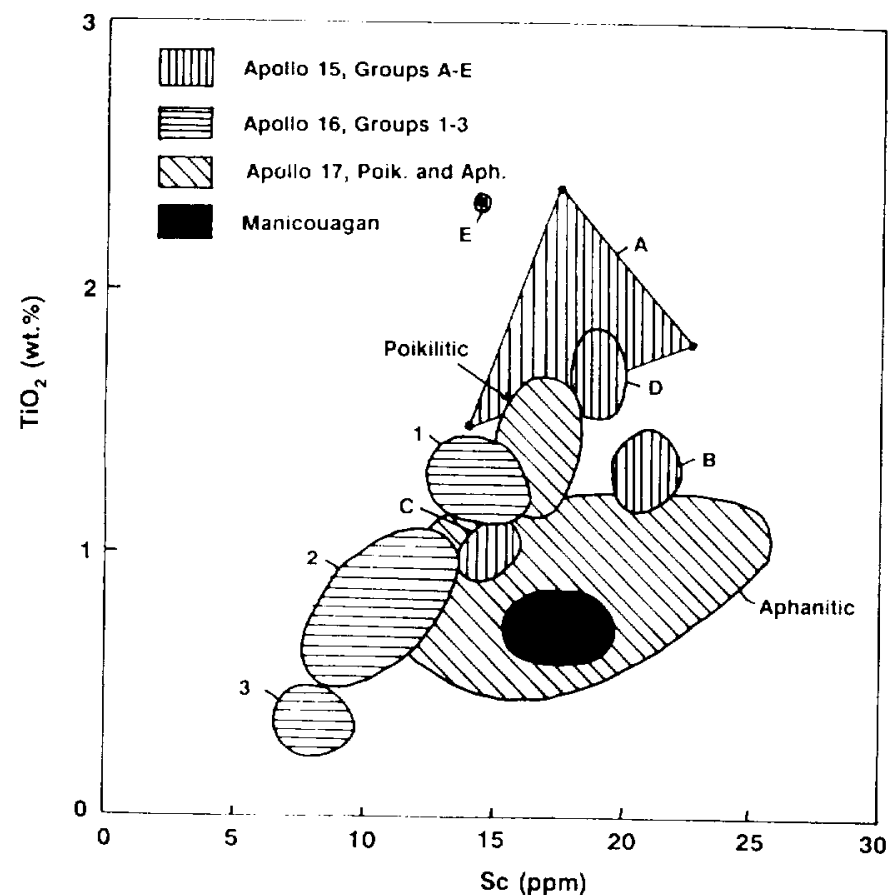

Figure 2. Concentration of $\mathrm{TiO}_{2}$ and $\mathrm{Sc}$ (two refractory elements) in basaltic impact melts from three highland landing sites on the Moon. Different groups are distinguished at each site: melt groups $1-3$ at Apollo 16 are defined by McKinley et al. (1984), "poikilitic" and "aphanatic" are the two melt categories at Apollo 17 (e.g., Spudis and Ryder, 198), groups A-E are found at the Apollo 15 site (Ryder and Spudis, 1987). The field of the melt sheet from the terrestrial Manicouagan crater is shown for comparison (data from the literature). Although showing considerable overlap, melts from a given site tend to have compositions that are (1) distinct from the local upper crust, implying exotic derivation (here interpreted as being from deep within the crust, formed during basin impact); and (2) distinct from each other, implying creation in different basin-forming impacts.

ited to upper crustal levels (Spudis et al., 1984). The crust may be as thick as $100 \pm 10 \mathrm{~km}$ in this region (Bills and Ferrari, 1976). Assuming that anorthosites are found mostly in the upper one-half of the crust (e.g., Ryder and Wood, 1977; Spudis and Davis, 1986), the anorthositic composition of Orientale ejecta suggests that the maximum depth of basin excavation is on the order of about $50 \mathrm{~km}$. Thus, the effective depth of excavation of this basin is about $0.1 \pm 0.02$ times the diameter of the excavation cavity (Spudis et al., 1984, 1988, 1989a), a result consistent with experiments (Stoffler et al., 1975), analysis of cratering geometries (Croft, 1981a), and the geology of terrestrial impact craters (Grieve et al., 1981).

Because basins throw out vast quantities of material and such ejection results in the redistribution of mass (creating gravity anomalies), the volume of material ejected by a basinforming impact might be a test for models of basin excavation. I have estimated the total volume of material ejected from the excavation cavity for five basins on the Moon (Table 1; Spudis, 1993) assuming a spherical Moon excavated by a hemispherical cavity to a depth equal to one-tenth its diameter (Croft, 1981a).

The range of estimates of ejecta volumes (Table 1 ) results from the uncertainty of the true size of the original crater; in some instances, this variation is quite large (e.g., Imbrium). I estimated the total amount of material excavated from the lunar mantle during basin formation, on the basis of approximations of crustal thickness from Bills and Ferrari (1976). Two of the basins may have been large enough to produce subcrustal (mantle) ejecta: the Serenitatis and Imbrium basins (Table 1). Both the Serenitatis and Imbrium basins have large quantities of mafic materials in their ejecta, which I interpret to be from the lower crust (Spudis, 1993), and mantle fragments could be contained within deposits that are partly buried by younger mare basalt flooding, within portions of their ejecta that were not sampled by a mission, or those that are not covered by remote-sensing data.

These estimates of ejecta volumes for lunar basins (Table 1) are comparable to those derived by other methods. Moore et al. (1974) used photogeology to estimate an excavated volume for Orientale of $4.5 \times 10^{6} \mathrm{~km}^{3}$. Scott (1974) analyzed the apparent mass deficit of the Orientale basin from orbital gravity data; he estimated that $5.3 \times 10^{6} \mathrm{~km}^{3}$ of material was excavated. More recently, Bratt et al. (1985) modeled the amounts of structural uplift of the crust-mantle boundary to estimate excavated volumes; they found a total excavated volume of 7 $\times 10^{6} \mathrm{~km}^{3}$ for the Orientale basin. These values may be compared with Table 1; I estimate that the Orientale basin excavated $7.7 \pm 2.7 \times 10^{6} \mathrm{~km}^{3}$ of crustal material. Thus, the proportional growth model applied to lunar basins predicts total excavated volumes that agree with observations for the Orientale basin.

Data from well-studied complex craters on the Earth suggest that the excavation cavity of complex craters is on the order of 0.5 to 0.65 times the diameter of the apparent crater (Gricve et al., 1981); the maximum depths of excavation are on the order of $0.09-0.12$ times the excavation cavity diameter (Grieve et al., 1981). These numbers compare favorably with the admittedly poorly resolved lunar values (e.g., Spudis, 1993), a conclusion substantiated by certain analytical methods (Croft, 1985). The relatively shallow effective depths of excavation predicted by these various models account for the relative paucity of very deep crustal or mantle materials within the returned Apollo lunar samples (Taylor, 1982; Wilhelms, 1987).

\section{BASIN RING FORMATION}

A wide variety of mechanisms has been proposed to account for the formation of basin rings (see review in Spudis, 1993). In my opinion, none of them are entirely plausible and the formation of rings constitutes the last great unsolved puzzle of multiring basin formation. Ring-forming mechanisms can be divided into two broad groups (see Pike and Spudis, 1987 and Spudis, 1993): (1) forcible uplift due to fluidization 
TABLE 1. INFERRED CAVITY DIMENSIONS AND TOTAL EXCAVATED VOLUMES FOR FIVE LUNAR MULTIRING BASINS*

\begin{tabular}{|c|c|c|c|c|c|c|c|}
\hline Basin & $\begin{array}{l}\text { Diameter }{ }^{\dagger} \\
\qquad(\mathrm{km})\end{array}$ & $\begin{array}{l}\mathrm{D}_{\mathrm{tc}}^{5} \\
(\mathrm{~km})\end{array}$ & $\underset{\text { excav. }}{\mathbf{d}^{5}}$ & $\underset{\left(10^{6} \mathrm{~km}^{3}\right)}{V_{\text {ejectum }}^{* \prime}}$ & $\underset{(\mathrm{km})}{T_{\text {crust }}{ }^{\ddagger}}$ & $\underset{\left(10^{6} \mathrm{~km}^{3}\right)}{\left.V_{\operatorname{man}}\right)}$ & $\% V_{m} 5$ \\
\hline Orientale & 930 & $582 \pm 77$ & $58 \pm 21$ & $7.7 \pm 2.7$ & 90 & $\cdots \cdots$ & $\ldots \ldots$ \\
\hline Nectaris & 860 & $544 \pm 73$ & $54 \pm 20$ & $6.3 \pm 2.2$ & 70 & $\cdots \cdots$ & $\ldots \ldots$ \\
\hline Crisium & 740 & $488 \pm 27$ & $49 \pm 13$ & $4.5 \pm 0.7$ & 60 & $\ldots . .$. & ….... \\
\hline Serenitatis & 920 & $572 \pm 76$ & $57 \pm 21$ & $7.3 \pm 2.5$ & 60 & 0 to 0.6 & 0 to 0.5 \\
\hline Imbrium & 1,160 & $685 \pm 88$ & $68 \pm 25$ & $12.5 \pm 5.4$ & 55 & 0.05 to 1.46 & 0.6 to 8.1 \\
\hline
\end{tabular}

-From Spudis, 1993.

tDiameter refers to basin main topographic rim, interpreted here as structurally equivalent to rims of smaller, complex craters. Crisium main rim diameter undertain (Spudis et al., 1989); $740 \mathrm{~km}$ diameter ring is current best estimate.

$5 \mathrm{D}_{\mathrm{tc}}$ refers to diameter of basin transient crater according to proportional growth model (Croft, 1981a, 1985; Spudis et al., 1984, 1988, 1989a). Values calculated from equation $D_{k}=(0.47 \pm 0.05) D+$ $(140 \pm 30)$; excavation depths, $d_{\text {excer }}=(0.1 \pm 0.02) D_{t c}$ from Spudis and Davis, 1986 .

*Ejecta volumes.

tCrustal thickness estimates at basin target sites from Bills and Ferrari, 1976.

$\$ 5 \% V_{m}$ refers to estimated percent of mantle material in basin ejecta.

of the target (e.g., Baldwin, 1981; Wilhelms, 1987); (2) concentric, brittle fracturing and failure of the target, on regional (megaterraces; Head, 1974) to global scales (lithospheric fracturing; Melosh, 1989). Geological evidence supports certain aspects of each of these models, but supports none of the models completely or unequivocally.

One constraint that has emerged from the examination of a variety of basins on a number of terrestrial planets is that basin rings are spaced at a constant factor, namely the famous $\sqrt{2}$ (Hartmann and Kuiper, 1962; Fielder, 1963; Hartmann and Wood, 1971; Pike and Spudis, 1987). Sometimes misunderstood, the " $\sqrt{2}$ rule" simply defined says that the diameter of any given ring of a multiring basin is a multiple of an integer power of $\sqrt{2}$, or,

$$
D_{n}=(\sqrt{2})^{N} D
$$

where $D_{n}$ is the diameter of any observed ring, $D$ is the basin rim diameter, and $\mathrm{N}$ is an integer (Pike and Spudis, 1987). Originally proposed only for the Orientale basin (Hartmann and Kuiper, 1962; Fielder, 1963), it has been found to be valid for basins on all of the terrestrial planets and some icy satellites (Pike and Spudis, 1987). Because geological evidence supports divergent ring-forming models, it may be that the ring-locating mechanism is different from the ring-forming mechanism (Pike and Spudis, 1987).

The topographic rim of basins (e.g., the Cordillera ring of the Orientale basin) is equivalent to the rims of smaller, complex craters (e.g., Copernicus). Such equivalence has long been assumed by most workers, including those that do not adhere to proportional growth models of basin formation (e.g., Wilhelms, 1987, p. 78). Wilhelms (1987) and I differ in that he believes that the main rim of craters marks the boundary of impact ex- cavation. This equation conflates an ephemeral feature, the transient cavity (produced during the excavation phase of basin formation) with a permanent feature, the crater rim (produced during the excavation phase of basin formation) with a permanent feature, the crater rim (produced during the modification phase). Study of both experimental craters (e.g., Stöffler et al., 1975) and terrestrial impact craters (e.g., Grieve, 1987) demonstrate that these two phases of crater formation are in fact distinct, even though they may overlap in time.

Immediately following the basin excavation phase, the region surrounding the excavation cavity is deformed and moves upward in response to the crustal unloading produced by excavation. This deformation and crustal adjustment produces at least some basin rings. I believe that the topographic rim of lunar basins is formed largely by structural uplift and subsequent collapse, specifically, by the formation of a megaterrace (Mackin, 1969; Gault, 1974; Head, 1974, 1977; Dence, 1976; Croft, 1981b). The fault origin of the Orientale Cordillera ring is evident in the deformation and offset of older structures in that region. The scarp-like appearance of both the Cordillera range of Orientale and the Altai ring of Nectaris are strongly suggestive of a structural origin. A structural exposure of preImbrian rocks within the Apennine front (e.g., Spudis and Ryder, 1985) supports a megaterrace origin for this part of the rim of the Imbrium basin.

The intermediate ring of basins may also be of structural origin, because older topography is often preserved inside of the main ring and sometimes inside the intermediate ring (Schultz and Spudis, 1978; Spudis, 1993). Such preservation would not be possible if the tsunami (Van Dorn, 1968; Baldwin, 1981) or nested-crater models (Wilhelms et al., 1977; Hodges and Wilhelms, 1978) were responsible for ring formation. Inner rings of basins (whose diameter is smaller 
than the inferred diameter of the transient cavity) may form either by oscillatory uplift (Murray, 1980; Grieve et al., 1981) or by structural uplift, followed by collapse (Head, 1977; Melosh and McKinnon, 1978; Schultz et al., 1981); either mechanism is compatible with the observed geological relations. The documentation of minor oscillatory movement in well-characterized craters on Earth (Grieve et al., 1981) suggests that this mode of origin for inner rings may be likely for lunar basins.

The origin of the outer rings of basins, exterior to the main rim is still enigmatic. These rings follow the same $\sqrt{2}$ spacing rule as interior rings, are usually less prominent topographically, and frequently display structural features, such as vents for the extrusion of mare basalts (Spudis, 1993). These relations suggest that the outer rings are scarps of structural origin, formed along zones of weakness established during the impact. Their age relative to the basin event is unknown; perhaps they form by lithospheric fracturing on a long-term basis, several million years after the basin impact (e.g., Hartman and Wood, 1971; Melosh and McKinnon, 1978).

The scenario for the formation of basin rings outlined above resembles none of the classic models of ring formation in pure form, but rather, embodies certain elements from all of the models. The main rim of the basin is dominantly a feature formed by structural collapse (megaterrace), inner rings are created by uplift followed by collapse (oscillating peaks), and outer rings reflect collapse of the lithosphere or basin target after the impact event (target strength). In my opinion, the most realistic model for ring development advocated to date is that of Grieve et al. (1981); this model incorporates elements from a variety of different mechanisms into a consistent and coherent scenario of the development of basin rings. If the conundrum of ring genesis can be resolved, we will possess a good understanding of all of the principal phases of formation of multiring basins.

\section{CONCLUSIONS}

Impacts large enough to form basins occur early in the history of all the terrestrial planes and such impacts have global (and catastrophic!) consequences. We must understand how basins form and evolve in order to completely comprehend planetary evolution. Although such impacts are energetic beyond all human experience, a variety of geological clues permit us to reconstruct the complex mechanics of basin formation and the planetary response to such an event. Much additional work remains to be done before we can fully understand these fascinating and enigmatic features.

\section{ACKNOWLEDGMENTS}

I thank R. B. Hargraves and R. W. Wichman for helpful review comments on the manuscript. This paper is Lunar and Planetary Institute Contribution Number 823.

\section{REFERENCES CITED}

Baldwin, R. B., 1981. On the tsunami theory of the origin of multi-ring basins, in Schultz, P. H., and Merrill, R. B., eds., Multi-ring basins: Proceedings, Lunar and Planetary Science 12A, p. 275-288

Bills, B. G., and Ferrari, A. J., 1976, Lunar crustal thickness: Proceedings, Lunar Science Conference 7, frontispiece.

Bratt, S. R., Solomon, S. C., Head, J. W., and Thurber, C. H., 1985, The deep structure of lunar basins: Implications for basin formation and modification: Journal of Geophysical Research, v. 90, p. 3049-3064.

Croft, S. K., 1981a, The excavation stage of basin formation: A qualitative model, in Schultz, P. H., and Merrill, R. B., eds., Multi-ring basins: Proceedings, Lunar and Planetary Science 12A, p. 207-225.

Croft, S. K., 1981b, The modification stage of basin formation: Conditions of ring formation, in Schultz, P. H., and Merrill, R. B., eds., Multi-ring basins: Proceedings, Lunar and Planetary Science 12A, p. 227-257.

Croft, S. K., 1985, The scaling of complex craters: Proceedings, Lunar and Planetary Science Conference 15: Journal of Geophysical Research, v. 90 , p. $\mathrm{C} 828-\mathrm{C} 842$

Dence, M. R., 1976, Notes toward an impact model for the Imbrian basin: Interdisciplinary Studies by the Imbrium Consortium. Volume 1: Lunar Science Institute Contribution 267D, p. 147-155.

Fielder, G., 1963, Nature of Junar maria: Nature, v. 198, p. 1256-1260.

Gault, D. E., 1974, Impact cratering, in Greeley, R., and Schultz, P., eds., A primer in lunar geology: National Aeronautics and Space Administration, NASA TM X-62359, p. 137-175.

Grieve, R.A.F., 1987, Terrestrial impact structures: Annual Reviews of Earth and Planetary Science, v. 15, p. 245-270.

Grieve, R.A.F., Robertson, P. B., and Dence, M. R., 1981, Constraints on the formation of ring impact structures, based on terrestrial data, in Schultz, P. H., and Merrill, R. B., eds., Multi-ring basins: Proceedings, Lunar and Planetary Science 12A, p. 37-57.

Hale, W. S., and Grieve, R.A.F., 1982, Volumetric analysis of complex lunar craters: Implications for basin ring formation: Proceedings, Lunar and Planetary Science Conference 13: Journal of Geophysical Research, v. 87 , p. A65-A76.

Hartmann, W. K., and Kuiper, G. P., 1962, Concentric structures surrounding lunar basins: Tucson, University of Arizona, Communications Lunar and Planetary Laboratory, v. 1, p. 55-66.

Hartmann, W. K. and Wood, C. A., 1971, Moon: Origin and evolution of multi-ring basins: The Moon, v. 3, p. 3-78.

Head, J. W., 1974, Orientale multi-ringed basin interior and implications for the petrogenesis of lunar highland samples: The Moon, v. 11, p. 327-356.

Head, J. W., 1976, Evidence for the sedimentary origin of Imbrium sculpture and lunar basin radial texture: The Moon, v. 15, p. 455-462.

Head, J. W., 1977, Origin of outer rings in lunar multi-ringed basins: Evidence from morphology and ring spacing, in Roddy, D. J., Pepin, R. O., and Merrill, R. B., eds., Impact and explosion cratering: New York, Pergamon Press, p. 563-573.

Hodges, C. A., and Wilhelms, D. E., 1978. Formation of lunar basin rings: Icarus, v. 34, p. 294-323,

King, J. S., and Scott, D. H., 1978, The significance of buried craters associated with basins on the Moon and Mars, in National Aeronautics and Space Administration, Reports of planetary geology program 1977-78: National Aeronautics and Space Administration, NASA TM-79729, p. 153-156.

Mackin, J. H., 1969, Origin of lunar maria: Geological Society of America Bulletin, v. 80 , p. $735-748$.

McCauley, J. F., 1977, Orientale and Caloris: Physics Earth Planetary Interiors, v. 15 , p. $220-250$.

McCormick, K., Taylor, G. J., Keil, K., Spudis, P. D., Grieve, R.A.F., and Ryder, G., 1989, Sources of clasts in terrestrial impact melts: Clues to the origin of LKFM: Proceedings, Lunar and Planetary Science Conference 
19. p. 691-696.

McKinley, J. P., Taylor, G. J., Keil, K., Ma, M. S., and Schmitt, R. A., 1984. Apollo 16: Impact melt sheets, contrasting nature of the Cayley plains and Descartes mountains, and geologic history: Proceedings, Lunar and Planetary Science Conference 14: Journal of Geophysical Research, v. 89 , p. B513-B524.

Melosh, H. J., 1989, Impact cratering: A geologic process: New York, Oxford University Press, 245 p.

Melosh, H. J., and McKinnon, W. B., 1978, The mechanics of ringed basin formation: Geophysical Research Letters, v. 5, p. 985-988.

Moore, H. J., Hodges, C. A., and Scott, D. H., 1974, Multi-ringed basinsIllustrated by Orientale and associated features: Proceedings, Lunar Science Conference 5, p. $71-100$.

Murray. J. B., 1980, Oscillating peak model of basin and crater formation: Moon and Planets, v. 22, p. 269-291.

Oberbeck, V. R., 1975. The role of ballistic erosion and sedimentation in lunar stratigraphy: Reviews Geophysics Space Physics, v. 13, p. 337-362.

Pike, R. J., 1980, Geometric interpretation of lunar craters: U.S. Geological Survey Professional Paper 1046-C, 77 p.

Pike, R. J. 1982, Crater peaks to basin rings: The transition on Mercury and other bodies, in National Aeronautics and Space Administration, Reports of planetary geology program-1982: National Aeronautics and Space Administration, NASA TM-85127, p. 117-119.

Pike, R. J., 1983, Large craters or small basins on the Moon: Proceedings, Lunar and Planetary Science 14: Houston, Lunar and Planetary Institute, p. $610-611$.

Pike. R. J., and Spudis, P. D., 1987. Basin-ring spacing on the Moon. Mercury, and Mars: Earth Moon and Planets, v. 39, p. 129-194.

Ryder, G., 1990, Lunar samples, lunar accretion, and the early bombardment of the Moon: Eos, Transactions American Geophysical Union. v. 71 , p. 313-333.

Ryder, G., and Spudis, P. D., 1987, Chemical composition and origin of Apollo 15 impact melts, in Proceedings, Lunar and Planetary Science Conference 17: Journal of Geophysical Research, v. 92, p. E432-E446.

Ryder, G., and Wood, J. A., 1977, Serenitatis and Imbrium impact melts: Implications for large-scale layering in the lunar crust: Proceedings, Lunar Science Conference 8, p. 655-668

Schultz, P. H., and Spudis, P. D., 1978, The dark ring of Orientale: Implications for pre-basin mare volcanism and a clue to the identification of the transient cavity rim: Proceedings, Lunar and Planetary Science 9 Houston, Lunar and Planetary Institute, p. 1033-1035.

Schultz, P. H., Orphal, D., Miller, B., Borden, W. F., and Larson, S. A., 1981, Multi-ring basin formation: Possible clues from impact cratering calculations, in Schultz, P. H., and Merrill, R. B., eds., Multi-ring basins: Proceedings. Lunar and Planetary Science 12A, p. 181-195.

Scott, D. H., 1972. Structural aspects of Imbrium sculpture, in National Aeronautics and Space Administration, Apollo 16 Preliminary Science Report: National Aeronautics and Space Administration, NASA SP-315, p. 29-31 to 29-33.

Scott, D. H., 1974, The geologic significance of some lunar gravity anomalies: Proceedings, Lunar Science Conference 5, p. 3025-3036.

Spudis, P. D., 1984, Apollo 16 site geology and impact melts: Implications for the geologic history of the lunar highlands: Proceedings, Lunar and Planetary Science 15: Journal of Geophysical Research, v. 89, p. C95-C107.

Spudis, P. D., 1993. The Geology of multi-ring impact basins: The Moon and other planets: Cambridge, England, Cambridge University Press, $263 \mathrm{p}$
Spudis, P. D., and Davis, P. A.. 1986, A chemical and petrological model of the lunar crust and implications for lunar crustal origin: Proceedings, Lunar and Planetary Science Conference 17: Journal of Geophysical Research, v. 91, p. E84-E90.

Spudis, P. D., and Ryder, G., 1981, Apollo 17 impact melts and their relation to the Serenitatis basin, in Schultz, P. H., and Merrill, R. B., eds., Multiring basins: Proceedings, Lunar and Planetary Science 12A, p. 133-148.

Spudis, P. D. and Ryder, G., 1985, Geology and petrology of the Apollo 15 landing site: Past, present, and future understanding: Eos, Transactions American Geophysical Union. v. 66, p. 721-726.

Spudis, P. D., Hawke, B. R., and Lucey, P. G., 1984, Composition of Orientale basin deposits and implications for the lunar basin-forming process: Proceedings, Lunar and Planetary Science Conference 15: Journal of Geophysical Research, v. 89, p. C197-C210.

Spudis, P. D., Hawke, B. R., and Lucey, P. G., 1988, Materials and formation of the Imbrium basin: Proceedings, Lunar and Planetary Science Conference 18: Lunar and Planetary Institute and Cambridge University Press, p. 155-168.

Spudis, P. D., Hawke, B. R., and Lucey, P. G., 1989a, Geology and deposits of the lunar Nectaris basin: Proceedings, Lunar and Planetary Science Conference, v. 19, p. 51-60.

Spudis, P. D., Hawke, B. R., and Lucey, P. G., 1989b, The lunar Crisium basin: Geology, rings, and deposits: Lunar and Planetary Science 20. Houston, Lunar and Planetary Institute, p. 1042-1043.

Spudis, P. D., Ryder, G., Taylor, G. J., McCormick, K. A., Keil, K., and Grieve, R.A.F., 1991, Sources of mineral fragments in impact melts 15445 and 15455: Toward the origin of low-K Fra Mauro basalt: Proceedings. Lunar and Planetary Science Conference, v. 21, p. 151-165.

Spudis, P. D., Hawke, B. R., Lucey, P. G., Taylor, G. J., and Peterson, C., 1992, Geology and deposits of the Humorum basin: Lunar and Planetary Science 23, p. 1345-1346.

Stoffler, D., Gault, D. E., Wedekind, J., and Polkowski, G., 1975, Experimental hypervelocity impact into quartz sand: Distribution and shock metamorphism of ejecta: Journal of Geophysical Research, v. 80, p. 4062-4077.

Taylor, S. R., 1982, Planetary science: A lunar perspective: Houston, Lunar and Planetary Institute Press, $481 \mathrm{p}$.

Van Dorn, W. G., 1968, Tsunamis on the Moon?: Nature, v. 220, p. 1102-1107.

Wichman. R. W. and Schultz, P. H., 1992, Variation in multi-ring basin structures as a function of impact angle: Conference on large meteorite im pacts and planetary evolution: Lunar and Planetary Institute Contribution 790, p. 81-81.

Wilhelms, D. E., 1976, Secondary impact craters of lunar basins: Proceedings, Lunar Science Conference 7, p. 2283-2901.

Wilhelms, D. E., 1987, The geologic history of the Moon: U.S. Geological Survey Professional Paper 1348, 302 p.

Wilhelms, D. E., 1993, To a rocky Moon: A geologist's history of lunar exploration: Tucson, University of Arizona Press, $477 \mathrm{p}$.

Wilhelms, D. E., Hodges, C. A., and Pike, R. J., 1977, Nested crater model of lunar ringed basins, in Roddy, D. J., Pepin, R. O., and Merrill, R. B., eds.. Impact and explosion cratering: New York, Pergamon Press, p. 539-562.

Wolfe, E. W.. Bailey, N. G., Lucchitta, B. K., Muehlberger, W. R., Scott, D. H., Sutton, R. L., and Wilshire, H. G., 1982, The geologic investigation of the Taurus-Littrow Valley: Apollo 17 landing site: U.S. Geological Survey Professional Paper 1080, $280 \mathrm{p}$.

MaNusCript ACCEPTED By the Society December 28, 1993 